\title{
NOTA A PROPOSITO DO ARTIGO «TERRAÇOS VERSUS LITOSTRATIGRAFIA E GEOCRONOLOGIA DO PLISTOCÉNICO E HOLOCÉNICO DA ZONA COSTEIRA DO MINHO (PORTUGAL)»
}

\author{
J. MEIRELES *
}

Resumo

\begin{abstract}
A presente nota constitui um comentário ao artigo intitulado «Terraços versus litostratigrafia e geocronologia do Plistocénico e Holocénico da zona costeira do Minho (Portugal)», da autoria de G. Soares de Carvalho e H. Granja, publicado no primeiro número da revista Estudos do Quaternário. Nela, o autor trata e refuta, num patamar de discussão científica, as críticas formuladas às investigações por ele realizadas, no decurso dos anos oitenta e noventa, na zona costeira do Minho (Portugal).
\end{abstract}

Abstract

\begin{abstract}
Note on the article 'Terraces versus lithostratigraphy and geochronology of the Pleistocene and Holocene of the Minho coastal zone (Portugal)' - The following note is a further comment on G. Soares de Carvalho and H. Granja's «Terraces versus lithostratigraphy and geochronology of the Pleistocene and Holocene of Minho coastal zone» article wich was published in this journal. The author discuss and refutes using scientific arguments the complaints stated to his research in the Minho coastal zone during the $80 / 90$ 's.
\end{abstract}

A edição de uma publicação científica, com carácter periódico, visando dar expressão e visibilidade à investigação desenvolvida sobre o Quaternário em Portugal, constitui, indiscutivelmente, motivo de regozijo e satisfação para a comunidade científica portuguesa, em geral e, compreensivelmente, no seio desta, para todos os que se dedicam ao estudo plurifacetado daquele período no nosso país, em particular. A iniciativa editorial levada a cabo pela Associação Portuguesa para o Estudo do Quaternário representa, por isso, um contributo decisivo para o desenvolvimento da pesquisa, dotando-a, pela primeira vez na sua história, de um meio de divulgação próprio, onde os seus agentes poderão, com regularidade, não apenas dar conta dos progressos e avanços operados no domínio do conhecimento, mas também promover o debate e confronto de ideias e perspectivas de investigação, claro indicador da própria vitalidade e dinamismo desta.

Este segundo aspecto, com reduzida tradição, é certo, no quadro da investigação nacional, deverá, no entanto, estar sujeito - pelo menos assim sucede nos meios científicos e editoriais em que, justamente, a sua existência se encontra desde há muito firmada a uma ética de funcionamento que, infelizmente, pensamos não ter sido devidamente acautelada no primeiro número da revista Estudos do Quaternário. Com efeito, e sem que tal represente qualquer recuo relativamente ao sentir enunciado no parágrafo anterior quanto à oportunidade e mérito da publicação em causa, não podemos deixar de manifestar a nossa profunda surpresa e, desde logo, discordância, pelo facto de, face à natureza e espírito do artigo intitulado
«Terraços versus Litostratigrafia e Geocronologia do Plistocénico e do Holocénico da zona costeira do Minho (Portugal)», da autoria de G. Soares de Carvalho e H. Granja, a sua direcção não ter criado as condições para que os autores nele visados tivessem tido a oportunidade de réplica no mesmo número. Mais entendemos que tal postura ética justificadamente se impunha, quanto o primeiro subscritor do mencionado texto desempenha as funções de Director da referida revista.

Vincada esta posição de princípio, a leitura do texto da autoria de G. Soares de Carvalho e H. Granja suscita-nos os seguintes comentários.

A sua construção obedece a uma estratégia que se afigura transparente: partindo do enunciado daquilo que consideram ser um conjunto de manifestas insuficiências, quer no domínio da manipulação de conceitos e terminologias, quer no âmbito da eleição e aplicação dos métodos e técnicas analíticas que suportam as interpretações sedimentogenéticas avançadas no quadro da investigação desenvolvida sobre o Quaternário do litoral do Minho, G. Soares de Carvalho e H. Granja procuram, por esta via, desacreditar tal pesquisa e, consequentemente, lançar o descrédito sobre a proposta de modelo evolutivo que dela emanou (MEIRELES, 1991; MEIRELES \& TEXIER, 1993). Atentemos, então, em tais insuficiências.

Assinalam o erro resultante do facto de considerarmos um terraço como uma unidade lito-estratigráfica. Contudo, eles próprios admitem, na parte introdutória do seu texto (CARVALHO \& GRANJA, 1997, p. 26), a possibilidade de um terraço poder representar uma geoforma associada a uma qualquer acumulação

\footnotetext{
* Unidade de Arqueologia da Universidade do Minho, Av. Central, n. ${ }^{\circ}$ 39, 4710-228 Braga, Portugal E-mail: jmeireles@ci.uminho.pt
} 
de sedimentos, independentemente da origem destes. Ora, foi justamente este o entendimento por nós adoptado e, aliás, claramente explicitado (MEIRELES, 1991, p.46), pelo que, neste contexto, continua a afigurar-se-nos legítimo considerar um terraço como uma unidade litoestratigráfica. Ainda a este propósito e em seu apoio, refira-se a própria definição de unidade litoestratigráfica consagrada no Guide Stratigraphique International, classification, terminologie et règles de procédures (tradução francesa) (HEDBERG, 1979 , p. 40): «(...) corps de couches géologiques qui est caractérisé principalement par un certain type de lithologie ou par l'association de plusieurs types lithologiques, ou par une propriété lithologique marquante et commune aux diverses couches considérées».

Insurgem-se, também, aqueles autores quanto à pretensão por nós assumida de adoptar, enquanto hipótese de trabalho, um novo quadro de referência cronoestratigráfico, na circunstância o estabelecido de acordo com a escala cronoestratigráfica dos fundos oceânicos. A este propósito convirá recordar que o nosso principal objectivo consistiu em procurar definir uma litoestratigrafia regional e tentar situar as suas unidades num quadro cronoestratigráfico pré-existente. Situando-se a nossa área de trabalho numa zona litoral e estando nela representados depósitos marinhos, defendemos então e continuamos a fazê-lo, a legitimidade de referenciação a um quadro cronológico também ele estabelecido em meio marinho e universalmente reconhecido. A circunstância de tal quadro não utilizar a terminologia definida pelo Código Estratigráfico Internacional, à semelhança, aliás, da esmagadora maioria das publicações versando sobre o Quaternário, não tem constituído motivo impeditivo da sua cada vez mais generalizada utilização. Tal circunstância não será certamente alheia ao reconhecimento, hoje em dia generalizado, das especificidades colocadas pela investigação no âmbito deste período e que levam os seus especialistas a admitir que «(...)Division of Quaternary strata into chronostratigraphic units is seldom straightforward, however, and problems arise that are not encountered in the earlier geological record» (LOWE \& WALKER, 1997, p.309).

No seu texto, salientam seguidamente os meus críticos a incorrecta utilização da palavra série, no quadro da expressão «série litoestratigráfica», uma vez que esta, e passamos a citar, «(..) se utiliza para designar uma unidade cronoestratigráfica» (p. 30). Desligado do seu contexto, ou seja, considerado individualmente, tal conceito reporta-se, de facto, à nomenclatura específica do domínio da cronoestratigrafia e, como tal, a sua utilização poderia ser vista como a prática de um erro formal. Contudo, haverá que, primeiramente, atender ao seu contexto de utilização e à presença da adjectivação «litoestratigráfica», que se nos afigura suficientemente explícita para que não possa dar azo a ambiguidades (de facto, a utilização do termo série é realizada enquanto sinónimo de sequência) e, sobretudo, ter presente, o que parecem esquecer G. Soares de Carvalho e H. Granja, que quando utilizada para designar uma unidade cronoestratigráfica tal palavra obedece, segundo, justamente, o Código Estratigráfico Internacional, a uma grafia específica (iniciada com maiúscula), que não é aquela que utilizo, nem tão pouco e surpreendentemente, a que utilizam aqueles autores!

De facto, quando se assume a postura fundamentalista de arautos do rigorismo formalista não basta, na prática, parecê-lo, é preciso, em coerência, sê-lo e tê-lo sido desde sempre. E sem procurar intencionalmente insuficiências do mesmo tipo das que me acusam de ter cometido, certamente encontraríamos nas publicações daqueles autores situações, porventura, análogas: atente-se, por exemplo e a propósito da Formação com tijuca da Aguçadoura, ao facto dela ainda não ter merecido qualquer representação cartográfica, dos seus limites laterais não se encontrarem ainda claramente estabelecidos, ou mesmo da sua designação não obedecer, em rigor e espírito, no que à menção do constituinte litológico do seu designativo se refere, ao normativo imposto pelo Código Estratigráfico Internacional.

Acusam-me, ainda, G. Soares de Carvalho e H. Granja, de algumas insuficiências no que concerne ao domínio das interpretações sedimentogenéticas. Para tanto, destacam a confusão (entenda-se, o desconhecimento da diferença de sentido analítico) entre morfoscopia e morfometria, reflectida pela legenda de um quadro, de uma página, de um trabalho que conta com largas centenas delas (MEIRELES, 1991). De facto e no que a este aspecto respeita, não encontramos justificação para o sucedido, a não ser aquela que passa, obviamente, pelo assumir de tratar-se de uma «gralha», aliás, tão evidente, quanto em nenhum local do texto ela é novamente reproduzida, muito menos no capítulo consagrado ao enunciado do suporte metodológico e técnico-analítico da investigação, onde a referência que é explicitamente realizada (p.70) diz unicamente respeito à morfometria (cálculo dos índices de achatamento e de desgaste de $1 .{ }^{*}$ ordem, aplicados aos elementos com uma dimensão superior a $10 \mathrm{~mm}$ ). Assim sendo, resta-nos apresentar desculpas pela presença, involuntária, é certo, de tão incómoda figura e agradecer àqueles autores o contributo desinteressado que. por via da sua chamada de atenção, prestaram à valorização do referido texto, colocando-o, simulta-neamenie. ao abrigo do aproveitamento que um qualquer espirito menos bem intencionado poderia fazer da presença da mencionada incorrecção. Desta situação, contudo, carregamos uma mágoa, que não conseguimos calar: muito teríamos apreciado que o então co-orientador oficial do referido trabalho. G. Soares de Carvalho, tivesse, desde logo. assinalado a ocorrência de tal lapso e 
não aguardasse quase cinco anos para o fazer, através de uma publicação.

Criticam ainda os mesmos autores a natureza meramente qualitativa das caracterizações da forma dos grãos de areia por mim efectuadas no decurso do mesmo trabalho. A este respeito, começarei por afirmar que não entendo os estudos analíticos como um fim em si, antes tenho deles a concepção de que são instrumentos destinados a encontrar respostas para questões e problemas concretos (partindo-se do princípio que os problemas são colocados e colocados correctamente). Por outro lado, a quantificação de determinados parâmetros, designadamente a morfoscopia dos grãos dos sedimentos, raramente se revela necessária e imprescindível, tendo em vista a concretização de uma abordagem aos processos da sedimentogénese. Veja-se, por exemplo, a este propósito, a posição adoptada por H.-E. REINECK \& I. B. SINGH (1980, p.141), ao afirmarem «(...) Form and roundness parameters do not provide any direct clues to depositional environments ... they can be helpful in typifying a given sand body». Com efeito, o reconhecimento e caracterização de determinados parâmetros descritivos (disposição morfológica, estruturas sedimentares representadas) assume, frequentemente, naquele contexto, uma muito maior pertinência, do que um mero somatório de análises desprovidas, quantas vezes, de qualquer outro critério que não seja o da mera quantificação indiscriminada.

Prosseguindo na sua crítica, G. Soares de Carvalho e H. Granja assinalam, ainda no quadro das insuficiências no domínio das interpretações sedimentogenéticas, a aplicação de parâmetros estatísticos ultrapassados (parâmetros de Trask, índice heterométrico de Cailleux), ignorando, assim, as novas metodologias e suas potencialidades, representadas pelos estatísticos dimensionais de Folk-Ward, pelo método dos momentos, pela análise da polimodalidade das distribuições de frequências dimensionais proposta por Visher, pelos diagramas de Passega e de Friedman.

A este propósito, convirá referir que o anátema lançado por aqueles autores sobre as técnicas analíticas por mim utilizadas, parece não ser partilhado por alguns conceituados especialistas nesse domínio. Senão, vejamos: H.-E. REINECK \& I. B. SINGH (1980, p. 132-133), ao abordarem a problemática da análise dimensional e respectivos parâmetros estatísticos, fazem-no e abstendo-se de qualquer apreciação/comparação valorativa entre ambos, reportando-se aos parâmetros, quer de Trask, quer de Folk-Ward; o mesmo se constata na publicação de J. MCMANUS (1995) quando, no quadro em que este autor refere o conjunto de fórmulas utilizadas para o cálculo dos já referidos parâmetros (p.78) são apresentadas, quer as que se reportam aos de Trask, quer as utilizadas nos de Folk-Ward; R. C. SELLEY (1992), por seu turno, ao tratar da apresentação/tratamento dos resultados da análise dimensional (p.45-48), exemplifica-o, justa- mente, com os parâmetros de Trask, acrescentando, «(...) These are the four statistical coefficients which are commonly calculated for a granulometric analysis (p.48)».

Quanto ao método dos momentos, que nos acusam de ignorar, D. W. LEWIS \& D. MCCONCHIE (1993) e para nos reportarmos a uma obra referida por G. Soares de Carvalho e H. Granja, referem, de facto, que «(...) The Method of Moments is widely used because it can be fully computerized)) (p. 116). Contudo, logo a seguir, advertem: «However, use of the method requires the complete size distribution of each sample - there can be no 'open tail'... Also, size values used in computations assume a 'normal' (Gaussian) distribution within each class that has been measured ...; this assumption is generally false and can distort results. The mode ... cannot be determined, nor can any polymodality in the distribution)) (p. 116). J. MCMANUS (1995), por seu turno e estabelecendo a comparação entre as técnicas gráficas e o método dos momentos, refere que «(...) Neither technique is 'better' than the other. Graphic techniques are especially appropriate for analysis of open ended distributions whereas the moment methods should not be applied» (p.78). De forma mais categórica pronunciam-se S. J. GALE \& P. G. Ho ARE (1991) quando, a propósito do método dos momentos, afir$\mathrm{mam} \ll(\ldots)$ this procedure is not generally recommended for the analysis of Quaternary materials. This is because the moment method can only be used when the nature of the entire particle-size distribution is known» (p.64); e depois acrescentam: «Although some workers recommend assuming that all the unmeasured fraction is coarser than a certain size, arbitrary decisions of this sort can rarely be justified and may result in the calculation of meaningless and misleading figures. The use of graphical measures is therefore recommended here» (p.65). Relativamente às possibilidades analíticas oferecidas pelos trabalhos de Visher, estes mesmos autores (GALE \& HOARE, 1991) começam por referir que «(...) Visher s approach to the analysis of particle-size data has been the subject of intense criticism» (p.73), procedendo, seguidamente e apoiados numa vasta bibliografia, ao enunciado daquelas que consideram ser as suas maiores fragilidades.

Em síntese, e para não nos alongarmos mais neste domínio, é actualmente reconhecido o limitado significado detido pelos resultados alcançados pelos sucessivos métodos estatísticos e de representação gráfica (nos quais se incluem os diagramas de Passega e de Friedman) que, ao longo dos anos, foram sendo desenvolvidos tendo em vista proceder, a partir dos dados da análise dimensional, à identificação dos ambientes de sedimentação (ver PETTIJOHN, 1975; REINECK \& SINGH, 1980; GALE \& HOARE, 1991; SELLEY, 1992; MCMANUS, 1995). Como assinalam DW. LEWIS \& D. MCCONCHIE (1993), «(...) Much 
effort has been expended for the last 50 years in discovering depositional envi-ronments of 'unknowns' by comparing their size distribution characteristics with a data base obtained from analyzing samples from 'known' environments; success has been limited because sampling procedures have largely been inadequate and because workers have been expecting too much. ... A few generalizations can be made ... but because a variety of processes act in most environments at a varied energy levels, application of such studies to samples from unknown environments is of limited valué» (p. 118-119). Por isso e como aconselham S. J. GALE \& P. G. HOARE (1991), «(..) Particle-size data must be used only in conjunction with other evidence to determine the conditions under which a material was deposited» (p.74). Em conclusão e por tudo o que para trás ficou dito, parece-nos que, no mínimo, as críticas e insuficiências apontadas por G. Soares de Carvalho e H. Granja deverão ser significativa e substantivamente relativizadas, a menos que os seus autores as joguem no campo dos argumentos de autoridade, mas aí, como é evidente, elas só terão o significado que se lhes quiser atribuir.

Prosseguem, depois, aqueles autores nas suas críticas, acusando-me, a propósito da cronologia por mim avançada para a plataforma e depósito marinho MIO, de proceder a uma revalidação do critério altimétrico (MEIRELES, 1991; MEIRELES \& TEXIER, 1993). A este respeito, gostaria de começar por recordar que tal cronologia, porque não apoiada em dados cronométricos, sempre foi apresentada como uma proposta. Esta, baseou-se numa argumentação de natureza morfo-pedoestratigráfica (p.228) e não, como o querem fazer crer os meus críticos, num critério exclusivamente altimétrico. Em nenhuma circunstância se fundamentou qualquer hipótese cronológica a partir da altitude absoluta verificada para o topo dos depósitos; aquela, apenas foi utilizada de um modo relativo, enquanto um critério descritivo no contexto de outros. Daí que, a comparação com os dados disponíveis para a fachada atlântica dos países do Sul da Europa e do Norte de África apenas tenha sido efectuada a posteriori (p. 229), com o intuito de constatar a similitude de situações. Não me parece, portanto, que encontre justificação a crítica efectuada por aqueles autores.

Continuam G. Soares de Carvalho e H. Granja, chamando depois a atenção para uma série de eventuais contradições resultantes do confronto entre o conjunto de dados cronométricos por eles obtidos e algumas das propostas cronológicas por mim efectuadas, o que, no seu entender, constitui mais uma demonstração cabal da completa inadequação do modelo que propus. Para tanto, afirmam não me ter eu apercebido, no sector costeiro localizado junto à foz do Cávado e para Sul deste rio, que a área com cotas próximas do terraço, que denomino por MIO, conserva depósitos holocénicos, nomeadamente a
Formação com tijuca da Aguçadoura, cujas datações a situam entre $1900 \pm 40$ e $360 \pm 50 \mathrm{BP}$.

A este respeito, importará começar por referir que a grande maioria dessas datas, foram obtidas num sector em que o terraço M 10 não se encontra directamente acessível à observação, pelo que não foi, em nenhum momento, por mim representado cartográficamente. Por outro lado, os depósitos datados (Formação com tijuca da Aguçadoura) foram atingidos com o recurso à técnica de vibrosondagem, pelo que a sua dimensão espacial, o seu significado ambiental e a sua altitude exacta são desconhecidos. A circunstância de alguns, localizados nas proximidades imediatas do estuário do Cávado, apresentarem cronologias muito recentes, afigura-se-me normal; podendo tratar-se, porventura, de depósitos associados aos processos de sedimentação actual e sub-actual do rio, cuja foz, desde há muito, é referenciada como tendo conhecido importantes modificações morfológicas e espaciais ao longo dos tempos. Quanto aos outros, reconhecidos mais para Sul, poderão, efectivamente, encontrar-se directamente associados a processos de sedimentação lagunar em meio confinado, de que existem, aliás e como refere H. GRANJA (1990, p.67-70), numerosos testemunhos históricos (fontes documentais) que atestam o sua presença/funcionamento na região, até às Idades Média e Moderna (no mínimo, século XVIII).

Antes de prosseguir, e ainda neste contexto, creio dever ser reposta a verdade quanto a uma afirmação efectuada por G. Soares de Carvalho e H. Granja. Referem estes autores no seu texto, ter eu posto em causa a existência do diatomito da Aguçadoura. Como qualquer pessoa de boa fé poderá comprovar (MEIRELES, 1991,p.265-266) a afirmação que produzi aplica-se, não à realidade do depósito em si, antes à eventualidade do mesmo se ver afectado por uma falha. Aliás, neste particular, limitei-me a seguir a posição adoptada por H. Granja, que, no seu trabalho (GRANJA, 1990 , p.58, fig. 19), se refere a tal facto como uma possibilidade.

Seguidamente e reportando-se, desta feita, ao sector setentrional do litoral minhoto (a Norte da foz do rio Lima), G. Soares de Carvalho e H. Granja referem ter aí reconhecido, novamente através da técnica de vibrosondagem, uma sequência representada por depósitos arenosos grosseiros, datados de 13860 $\pm 440 \mathrm{BP}$, a que se sobrepõem depósitos mais finos. Estes últimos corresponderiam, segundo aqueles autores, aos depósitos de tipo lagunar por mim identificados, o que, obviamente, e dado o posicionamento estratigráfico daqueles, invalidaria a proposta de cronologia que apresentei e que associava o seu estabelecimento a uma pulsação positiva do final do último interglaciar. Posteriormente, os mesmos autores afirmam, ainda, que tais depósitos têm semelhanças, quer com a Formação areno-limosa do litoral, quer com os depósitos coluvionares que igualmente identifiquei 
na região e que considerei anteriores ao último interglaciar ou constituídos no decurso do último glaciar. Deste conjunto de circunstâncias concluem, naturalmente, da total inoperância do modelo que propus.

Para melhor situar este conjunto de afirmações, gostaria de começar por mencionar que, no quadro da sequência litoestratigráfica que tive a oportunidade de definir para o litoral do Minho, os depósitos que considerei de tipo lagunar (depósitos $l$ ) são antecedidos, designadamente, por uma primeira geração de coluviões (as coluviões antigas $\mathrm{Ca}$, para as quais foi avançada uma hipótese cronológica que situa o seu estabelecimento no penúltimo período glaciar e que integram o terraço marinho M9), por um depósito marinho (o depósito MIO, atribuído ao último interglaciar e que ocupa a base da sequência representada no terraço marinho MIO) e por uma segunda geração de coluviões (as coluviões recentes Cri, para as quais foi proposta uma cronologia identificada com uma pulsação fria do estádio isotópico 5); por outro lado, esses mesmos depósitos são precedidos por outras duas gerações de unidades coluvionares (as coluviões recentes $\mathrm{Cr} 2$ e $\mathrm{Cr} 3$, as quais foram atribuídas a uma fase indeterminada de degradação climática do último glaciar e ao Tardiglaciar ou ao Holocénico inferior, respe-ctivamente).

Ora, não tendo tido a possibilidade a observar nenhum depósito que se identifique com aquele datado por G. Soares de Carvalho e H. Granja (reconhecido, recorde-se, através de vibrosondagem), interrogo-me sobre que critérios se fundamentam estes autores para, tão categoricamente, o identificarem com os depósitos de tipo lagunar por mim assinalados. Será o critério altimétrico? Depois, quando afirmam que os mesmos depósitos (que, assinale-se, haviam acabado de fazer corresponder aos depósitos lagunares) têm semelhanças com a Formação areno-limosa do litoral e com as coluviões que eu havia identificado (quais?), cabe duplamente perguntar, afinal, quem corresponde a quê? Com que fundamentação? Ou será que, mais uma vez, nos situamos no plano dos argumentos de autoridade? Por último, importa ainda chamar a atenção para um outro dado, que reputo de grande importância. No seu texto, G. Soares de Carvalho e H. Granja fornecem uma segunda data (>42 370 B P) para um outro depósito, rico em elementos carbonosos, que, explicitamente, admitem eu ter assinalado; esquecem-se, contudo, de mencionar, que ele corresponde, justamente, aos depósitos que considerei de tipo lagunar (MEIRELES, 1991, p.241) e que atribuí, recorde-se, a uma fase temperada do último interglaciar. Assim, penso poder afirmar que as datas fornecidas pelos meus críticos não questionam, antes pelo contrário, as hipóteses cronológicas que propus.

De qualquer modo, o modelo evolutivo que construí, alicerçado em pesquisas concretizadas entre a foz do rio Minho e a zona da Aguçadoura (e não apenas na zona litoral entre as fozes dos rios Lima e Minho, como querem fazer crer G. Soares de Carvalho e H. Granja), apoia-se num conjunto de evidências morfológicas e pedoestratigráficas, que procurei sintetizar sob a forma de vários documentos cartográficos e outro tipo de representações gráficas e que estão acessíveis a qualquer pessoa que os queira analisar não partindo de ideias pré-concebidas. Em contrapartida, o modelo de duas únicas plataformas escalonadas proposto por aqueles autores, não me parece fundamentado em nenhuma evidência que se traduza pela existência de uma única ruptura morfológica absolutamente marcante, que o possajustificar.

A argumentação e as evidências regionais de natureza neotectónica que é suposto confirmarem tal modelo, continuam, em meu entender, a ser pouco convincentes. Com efeito, os dados mencionados directamente controláveis (cortes geológicos/ afloramentos) estão longe de assumir um estatuto decisivo. Tratar-se-ão efectivamente de falhas que afectam a cobertura sedimentar recente (plistocénica e holocénica)? Se sim, estarão elas relacionadas com a actividade neotectónica, ou resultarão antes de outros fenómenos que poderão nada ter a ver com ela (escorregamentos em massa)? O texto de G. Soares de Carvalho e H. Granja não proporciona, mais uma vez, qualquer evidência regional convincente. Quanto aos argumentos de carácter indirecto (acidentes antigos que teriam sido reactivados), já anteriormente tive ocasião de sobre eles me pronunciar (MEIRELES, 1991). Para concluir, refira-se que os estudos realizados por J. M. A. DIAS $(1985,1987)$ sobre a plataforma continental contígua, permitiram a este autor estabelecer uma curva da subida do nível médio das águas do oceano sensivelmente idêntica às que haviam sido definidas para outras zonas da fachada atlântica do Sul da Europa e que no âmbito dela não se detecta a ocorrência de qualquer anomalia susceptível de ser atribuída a movimentos tectónicos recentes.

Aqui chegado, e pela minha parte, considero encerrada esta polémica.

Braga, Janeiro de 1999

A GRADECIMENTOS

Quero expressar, o meu agradecimento a J.-P Texier, que acedeu ler o conteúdo desta pequena nota, bem como à Associação Portuguesa para o Estudo do Quaternário que possibilitou a sua publicação. Pelos seus contributos e sugestões, os meus agradecimentos são igualmente extensivos aos avaliadores oficiais convidados a pronunciar-se sobre este texto. 
B IB LIOGR A FIA

BRUM FERREIRA, A. (1994) - Uma tese moderna sobre o quaternário do litoral do Minho, Finisterra, XXIX, 59, p. 391-396.

CARVALHO, G. S.; GRANJA, H. M. (1997) - Terraços versus litostratigrafia e geocronologia do Plistocénico e do Holocénico da zona costeira do Minho (Portugal), Estudos do Quaternário, 1, p. $25-40$.

Di a s, J. M. A. (1985) - Registos da migração da linha de costa nos últimos 18000 anos na plataforma continental portuguesa setentrional. Actas da 1." Reunião do Quaternário Ibérico (vol.I), Lisboa, p. 281-295.

DIAS, J. M. A. (1987) —Dinâmica sedimentar e evolução recente da plataforma continental portuguesa setentrional, Tese de Doutoramento, Universidade de Lisboa, Lisboa, 384 p.

GALE, S. J.; HOARE, P. G. (1991) - Quaternary Sediments. Petrographic Methods for the Study of Unlithified Rocks, John Wiley \& Sons, New York, 323 p.

GRANJA, H. M. (1990) - Repensar a geodinâmica da zona costeira: o passado e o presente. Que futuro?, Tese de Doutoramento, Universidade do Minho, Braga, policopiado, $347 \mathrm{p}$.
HEDBERG. H. (dir.) »1979» — Guide Stratigraphique International. Classification, lermúmtogie et regies de procedures, Doin Editeurs, Paris. 233 p.

Lewis, D. W.: M c Cow me. D. (1993) - Analytical Sedimentology, Chapman \& HalL Ne»- York. 19? p.

Lowe, J. J.; Walker. M. i. C. < 19971 - Reconstructing Quaternary Environments. Longman. Harlow. 446 p.

McManus, J. (1995) - «Grain size determination and interpretation», in Tucker. M. (ed.). Techniques in Sedimentology, Blackwell Science, Oxford, p. 63-85.

MEIRELES, J. (1991) - As indústrias líticas pré-históricas do litoral minhoto (Portugal) no seu contexto cronoestratigráfico $e$ paleoambiental, Tese de Doutoramento, Universidade do Minho, Braga, policopiado. $654 \mathrm{p}$.

MEIRELES, J.; TEXIER, J.-P. (1993) - O Quaternário do Litoral do Minho. Uma síntese lito e cronoestratigráfica. Actas da 3." Reunião do Quaternário Ibérico. Coimbra, p. 395-408.

PETTIJOHN, F. J. (1975) - Sedimentary Rocks. Harper \& Row, New York, $628 \mathrm{p}$.

REINECK, H.-E.; SINGH, LB. (1980) - Depositional Sedimentary Environments, Springer-Verlag. Berlin. 551 p.

SELLEY, R.C. (1992) - Applied Sedimentology. Academic Press, London, 446 p. 